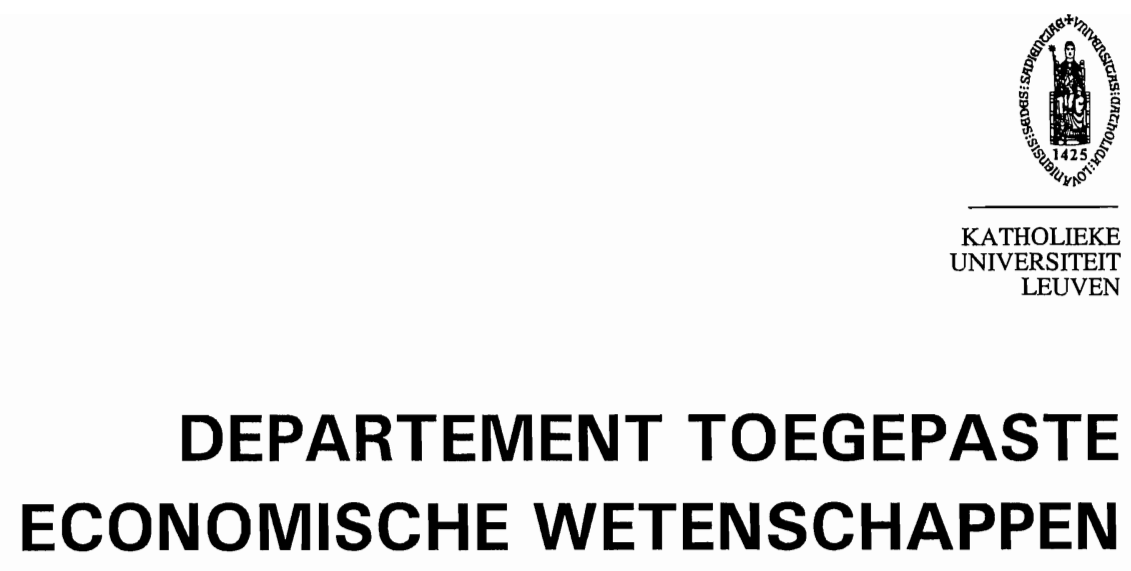

RESEARCH REPORT 0247

LIBERALIZING A DISTRIBUTION SYSTEM:

THE EUROPEAN CAR MARKET

by

R. BRENKERS

F. VERBOVEN 


\title{
Liberalizing a Distribution System: the European Car Market*
}

\author{
Randy Brenkers \\ Frank Verboven \\ K.U. Leuven \\ K.U. Leuven and C.E.P.R.
}

This version: September 2002

\begin{abstract}
We quantify the competitive effects of removing vertical restraints, based on the recent proposals to liberalize the selective and exclusive distribution system in the European car market. We estimate a differentiated products demand system for new cars and specify a model of oligopoly pricing under the current distribution regime. We then perform several policy experiments: the creation of international intrabrand competition (cross-border trade) and a possible strenghtening of national intrabrand competition. Our approach may also be useful to assess the competitive effects of vertical restraints in other applications.
\end{abstract}

${ }^{*}$ We thank seminar participants at the K.U.Leuven, University of Chicago GSB and University of Cyprus in Spring 2002. We gratefully acknowledge financial support by the Flemish Science Foundation (Fonds Wetenschappelijk Onderzoek Research Grant no. G.0231.99). 


\section{Introduction}

Vertical agreements between firms have been the subject of a long and intense debate in competition policy. In the U.S. the debate has focused around the question of which type of vertical restraints should be per se illegal, and which can be treated under a rule of reason approach. Price restraints (resale price maintenance) have generally been treated as per se illegal. Non-price restraints, such as exclusive territories, have often received a rule of reason treatment, implying a consideration of both anti-competitive effects and efficiencies. In the E.U. vertical restraints are prohibited, but exemptions are allowed when efficiencies occur and consumers receive a fair part the resulting benefits. ${ }^{1}$ The E.U. thus roughly follows a rule of reason approach by accounting for both the anti-competitive effects and efficiencies of vertical restraints. An important additional concern in Europe has typically been the extent to which the vertical restraints are compatible with the common market and achieve the goals of economic integration. Despite this additional concern, it seems fair to say that the E.U. has followed a more lenient approach than the U.S., which is reflected in the number of granted individual exemptions and block exemptions for vertical restraints.

The selective and exclusive distribution system for the European car market is a wellknown example of a block exemption. It has been in place since 1985 and institutionalized a series of previously existing vertical restraints as acceptable practices for the whole industry. The system allows manufacturers to select authorized dealers and to assign them territorial exclusivity. The industry has defended the system based on efficiency considerations, such as the need to control a dealer network that offers high quality sales and after-sales services. At the same time, consumer organizations have pointed out the potential anti-competitive effects arising from the system and the conflict with the European integration objectives. In particular, it has been argued that the distribution system offers only limited opportunity for cross-border arbitrage to eliminate the large and persistent international price differentials.

Since the block exemption expires in September 2002, the European Commission has prepared a detailed investigation into the benefits and the costs of alternative distribution systems. The result of this investigation is a new Regulation to create a system that generates more flexibility. It allows the manufacturers to impose either selectivity or territorial exclusivity on their dealers, but no longer a combination of both. ${ }^{2}$ The result of the proposed liberalization is the promotion of intrabrand competition, i.e. competition between dealers of the same brand, both at the national and at the international level. This may lead to a

\footnotetext{
${ }^{1}$ Art. 81 (1) of the Treaty of Rome contains the prohibition part, whereas Art. 81 (3) refers to the conditions under which exemptions are allowed. Note that Art. 81 applies to horizontal agreements as well.

${ }^{2}$ The new Regulation is available at the Commission's car sector website at http://europa.eu.int/comm/competition/car_sector.
} 
reduction in several anti-competitive distortions. At the international level, the promotion of intrabrand competition has the effect of eliminating the feasibility of international price discrimination. At the national level, the promotion of intrabrand competition may have the additional effect of eliminating a double marginalization problem, which can serve as a tacit collusion device to reduce the degree of competition between manufacturers.

The purpose of this paper is to quantify the competitive effects from the proposed liberalizations of the vertical restraints. To accomplish this, we progress in several steps. First, we estimate a differentiated products demand model for new cars. Next, we specify oligopoly pricing under the current distribution system with selectivity and exclusivity. We consider two possible scenarios. In the first scenario, the current system only limits international intrabrand competition, and hence enables international price discrimination. In the second scenario, the current system also limits national intrabrand competition and hence may serve as a tacit collusion device in addition to a price discrimination mechanism. Finally, we specify oligopoly pricing after liberalization and quantify the price and welfare changes in the new equilibrium. There are two possible changes from liberalization. International intrabrand competition is stimulated, so that the incentives for international price discrimination decline. Furthermore, national intrabrand competition may be created, at least to the extent that this was effectively limited before liberalization (i.e. the second scenario). This implies the tacit collusion device is eliminated.

Our analysis indicates that liberalizing the vertical restraints would have the following effects under the two alternative scenarios.

(1) If the existing system already entails sufficient national intrabrand competition, then liberalization mainly leads to a reduction in international price discrimination. Consumer surplus and total welfare may increase by an amount between zero and 1.6-2 billion Euro per year, depending on whether there are differences in conduct across countries (i.e. collusion).

(2) If the existing system effectively limits national intrabrand competition, then liberalization may lead to both reduced international price discrimination and to the elimination of tacit collusion. The computed consumer and welfare gains become much larger: consumer surplus would increase by about $10 \%$, and total welfare would go up by 6-8 billion Euro per year. We warn, however, that these large competitive gains must be balanced against potentially large efficiency losses in this case. Indeed, we also find that the manufacturing sector would experience a very substantial profit increase from liberalization, so that the existing system (the result of intensive industry efforts) may presumably only be rationalized by 
the presence important efficiencies.

In sum, the policy maker may either adopt the first scenario (i.e. assume the current system does not limit national intrabrand competition) and arrive at annual welfare gains between zero and 1.6-2 billion Euro. Or it may adopt the second scenario and arrive at much larger competitive gains, but then a more detailed quantification of the efficiency losses is indispensable.

During the past decade competition policy has spent an increasing amount of attention to oligopoly models with differentiated products to quantify competitive effects. This trend has been limited exclusively to the analysis of horizontal mergers. For studies based on actual cases and/or hypothetical mergers, see Hausman, Leonard and Zona (1994), Werden and Froeb (1994), Jayaratne and Shapiro (2000), Nevo (2000), Ivaldi and Verboven (2001) and Pinkse and Slade (2001). Our analysis shows that empirical oligopoly models can also assist in other areas of antitrust, such as vertical restraints, provided that the assumptions on oligopoly behavior are appropriately modified. The merger studies typically assume multi-product price-setting firms, and consider the effects of changing the product ownership matrix. Our oligopoly model explicitly accounts for the effects of selectivity and territorial exclusivity on international and national intrabrand competition. We model international intrabrand competition by imposing constraints on cross-country markup differentials after liberalization. See Davidson, Dewatripont, Ginsburgh and Labbé (1989) for a simplified theoretical framework with price constraints. National intrabrand competition, and the possible absence thereof before liberalization, is modelled by explicitly specifying the strategic interaction between the manufacturers and retailers. This was inspired by Rey and Stiglitz' (1995) theoretical analysis of tacit collusion under territorial exclusivity. ${ }^{3}$

The outline of the paper is as follows. In section 2 we discuss the role of selectivity and exclusivity in reducing international and national intrabrand competition (with a more detailed analysis in the Appendix). This section serves as the basis for the specification of the model, which is developed in section 3. Section 4 presents the parameters estimates based on a large data set for the car market before liberalization. Section 5 discusses the

\footnotetext{
${ }^{3}$ To model the absence of intrabrand competition before liberalization, we generalized Rey and Stiglitz' (1995) model to fit the details of the European car market. During the writing of this paper, we became aware of an emerging empirical literature in marketing that is closely related to our empirical model of the manufacturer-retailer relationship and that grew independent of Rey and Stiglitz' analysis and our empirical application. See Sudhir (2001), Villas-Boas and Zhao (2001) and Berto Villas-Boas (2002). Whereas these papers focus on testing alternative models of vertical interaction, our focus is on simulating the changes in equilibrium to liberalization. A common feature of both approaches is that wholesale prices (in addition to marginal costs) are not observed, but rather recovered from a model of the manufacturer-retailer relationship.
} 
effects of the liberalization on prices, profits and welfare. Extensions and conclusions follow in section 6 .

\section{The selective and exclusive distribution system}

\subsection{The current system and proposals for reform}

We begin with a review of the essential features of the selective and exclusive distribution system for cars, and the recently proposed liberalization measures. The Appendix provides a considerably more detailed discussion. Selectivity and territorial exclusivity have in common that they restrict the number of authorized distributors and the possibilities of resale. The difference lies in how these restrictions work. Selectivity means that each manufacturer can choose its dealers, based on qualitative or quantitative criteria. To protect the selective relationship, the manufacturer can prohibit its dealers to sell cars to independent resellers. Dealers may thus only sell to end-consumers, or to intermediaries with a written consumer authorization. Territorial exclusivity refers to the manufacturers' right to appoint only one dealer in a geographically limited territory. Dealers can therefore not maintain branches outside their own contract territory. We focus on two potential anti-competitive effects arising from the combination of selectivity and exclusivity. Both effects concern a reduction of intrabrand competition, i.e. competition between dealers selling the same brand.

\section{International intrabrand competition and price discrimination}

When selectivity and exclusivity are combined, cross-border arbitrage possibilities are limited. The rights of end-consumers to purchase cars abroad are in principle protected. But selectivity prevents independent resellers to systematically engage in arbitrage, while exclusivity prevents the authorized dealers to set up foreign branches to take advantage of price differentials. The result is a lack of international intrabrand competition, enabling the manufacturers to engage in international price discrimination. The lack of international intrabrand competition has been documented extensively. For example, BEUC (1992) and Goldberg and Verboven (2001) report evidence of very limited parallel imports (in the range of $0-2 \%$ of total sales), despite the large international price differentials.

\section{National intrabrand competition and tacit collusion}

Selectivity and exclusivity have an additional potential effect on intrabrand competition within a country. As analyzed by Rey and Stiglitz (1995), a limited degree of intrabrand competition creates a double marginalization effect, which serves to reduce the degree of 
competition between the manufacturers. ${ }^{4}$ As a result, equilibrium prices will increase and profits may be higher than under non-cooperative Bertrand pricing, a form of tacit collusion between manufacturers. In practice, it is not clear whether the distribution system effectively succeeds in limiting intrabrand competition also at the national level. For example, the U.K. Competition Commission quotes the number of $39 \%$ as the proportion of out-of-territory sales (within a country). It interprets this as a small number because of the high degree of urbanization and commuting. The industry, in contrast, would interpret this number as an indication that intrabrand competition within a country is high.

\section{The 2002 proposals for liberalization}

The Commission's proposed liberalization consists of essentially a more flexible system, where manufacturers may choose to adopt either selectivity or exclusivity, but no longer the combination of both. This has the following possible effects. First, it stimulates international intrabrand competition, either by independent resellers (if exclusivity is chosen) or by the foreign branches of authorized dealers (if selectivity is chosen). This reduces the feasibility of international price discrimination. Second, it stimulates national intrabrand competition, at least to the extent that this was effectively limited under the existing system. This would have the effect of eliminating the tacit collusion device.

\subsection{Overview of the model}

To assess the economic effects of the liberalization, we take into account the above critical features of selectivity and exclusivity to specify a model of demand and oligopoly pricing. Based on a set of assumptions and the available statistical information (including market shares and prices), the model forms the basis for measuring market power before liberalization, as well as predicting market power afterwards.

The first step specifies the demand for new cars. In the spirit of some recent merger studies this step may be viewed as a complement (or a substitute?) of the more traditional market definition analysis. Consistent with the previous discussion on the combined effect of selectivity and exclusivity, the demand model assumes there is no international intrabrand competition, i.e. no cross-border trade, and then specifies the substitution patterns within the geographically segmented markets.

The second step models oligopoly pricing before the liberalization of the distribution system. In contrast to the previous literature on oligopoly pricing in the car market, we

\footnotetext{
${ }^{4}$ Rey and Stiglitz' analysis mentions territorial exclusivity as a mechanism to eliminate (or reduce) intrabrand competition. Yet selectivity works as a complementary device, since it eliminates the role of independent resellers in intrabrand competition.
} 
explicitly account for the role of intrabrand competition. The above discussion showed that the current system limits international intrabrand competition, but it is not so obvious to which extent the system effectively limits national intrabrand competition. We respond to this choice problem by considering two alternative benchmark scenarios of pricing under the distribution system before liberalization. In the first scenario there is no international intrabrand competition (as already reflected in the demand specification), but there is full national intrabrand competition. In the second scenario, there is again no international intrabrand competition, and there is also limited national intrabrand competition.

The final step models oligopoly pricing after liberalization. Two effects may arise. First, the removal of either selectivity or exclusivity increases international intrabrand competition, due to cross-border trade activities by either independent resellers (if selectivity is abandoned) or by foreign branches by the authorized dealers (if exclusivity is abandoned). Second, there may be an increase in national intrabrand competition, at least to the extent that this was limited under the existing system (second scenario). To account for these effects, we model oligopoly pricing after liberalization as full national intrabrand competition, subject to the constraints on international price discrimination.

\section{The model}

\subsection{Demand}

There are $M$ national markets; in each market $m$ there are $L_{m}$ potential consumers. A consumer $i$ located in market $m$ can choose among the $J$ differentiated products. Assume that cross-border arbitrage costs are prohibitive so that consumers do not consider to purchase a car in another market than where they are located. This assumption allows us to suppress the market subscript $m$ for now; we will, however, need to explicitly reintroduce it below. A consumer $i$ 's conditional indirect utility from product $j=1, \ldots, J$ is given by:

$$
\begin{aligned}
u_{i j} & =x_{j}^{\prime} \beta-\alpha p_{j}+\xi_{j}+\varepsilon_{i j} \\
& \equiv \delta_{j}+\varepsilon_{i j}
\end{aligned}
$$

where $\delta_{j}$ is the mean utility, which is common to all consumers, and $\varepsilon_{i j}$ is the (mean zero) individual-specific utility term. The mean utility $\delta_{j}$ depends on $x_{j}$, a $K$-dimensional vector of product characteristics, on $p_{j}$, the price of product $j$, and on $\xi_{j}$, an unobserved product valuation. The observed product characteristics in $x_{j}$ are horsepower, fuel efficiency, size of the car, etc... The unobserved (to the econometrician) product characteristic $\xi_{j}$ may 
include style, image, advertizing, etc. Consumers may decide not to purchase any product. In this case they choose the outside good for which the mean part of the indirect utility $\delta_{0}$ is normalized to 0 , so that $u_{i 0}=\varepsilon_{i 0}$.

To model the distribution of the individual-specific utility term $\varepsilon_{i j}$ we follow the assumptions of a two-level nested logit model. Assume the national market can be partitioned into $G$ different groups. Each group $g$ can be further partitioned in $H_{g}$ subgroups. Each subgroup $h$ contains $J_{h g}$ products, $\sum_{g=1}^{G} \sum_{h=1}^{H_{g}} J_{h g}=J$. According to the distributional assumptions of the nested logit model consumers may have correlated preferences across all products of the same subgroup, and (no stronger) correlated preferences across all products of the same group but a different subgroup. The interpretation is that products belonging to the same subgroup or group share a common set of features, and that consumers have correlated preferences over these features. In the car market, marketing classifications and previous studies by e.g. Goldberg (1995) and Goldberg and Verboven (1996) partition the national markets into five groups according to "market segment", or "class": subcompact, compact, intermediate, standard and luxury. A sixth group is added and reserved exclusively for the outside good. The idea is that cars from the same market segment share a common set of features such as size and prestige, often as the result of deliberate marketing efforts. Each of the five main market segments is further subdivided in two subgroups according to the country of origin: domestic or foreign. Cars from the same country of origin (domestic or foreign) share additional common features, e.g. the image or style. Since the domestic firms typically have a substantially more dense dealer network than the foreign firms, an additional common feature of cars from same origin is the average dealer distance for obtaining after-sales services.

If consumers choose one unit of the product that maximizes utility, the distributional assumptions of the nested logit model yield the following choice probability or market share for each product $j$, as a function of the $J \times 1$ price vector $p$ :

$$
s_{j}(p)=\frac{\exp \left(\delta_{j} /\left(1-\sigma_{h g}\right)\right)}{\exp \left(I_{h g} /\left(1-\sigma_{h g}\right)\right)} \frac{\exp \left(I_{h g} /\left(1-\sigma_{g}\right)\right)}{\exp \left(I_{g} /\left(1-\sigma_{g}\right)\right)} \frac{\exp \left(I_{g}\right)}{\exp (I)}
$$

where $I_{h g}, I_{g}$, and $I$, are "inclusive values", defined by: 


$$
\begin{aligned}
I_{h g} & \equiv\left(1-\sigma_{h g}\right) \ln \sum_{j=1}^{J_{h g}} \exp \left(\delta_{j} /\left(1-\sigma_{h g}\right)\right) \\
I_{g} & \equiv\left(1-\sigma_{g}\right) \ln \sum_{h=1}^{H_{g}} \exp \left(I_{h g} /\left(1-\sigma_{g}\right)\right) \\
I & \equiv \ln \sum_{g=1}^{G} \exp \left(I_{g}\right)
\end{aligned}
$$

The parameters $\sigma_{h g}$ and $\sigma_{g}$ are the nested logit random coefficients associated to the subgroups $h$ of $g$ and the groups $g$. They measure the degree of correlation of consumer preferences for cars belonging to the same subgroups or groups. The conditions on McFadden's (1978) GEV model imply that the model is consistent with random utility maximization if $1 \geq \sigma_{h g} \geq \sigma_{g} \geq 0$. In a typical case where $1>\sigma_{h g}>\sigma_{g}>0$, consumer preferences are more strongly correlated across products of the same subgroup than across products of a different subgroup within the same group; preferences are in turn more correlated across these products than across products from a different group. As $\sigma_{h g}$ goes to 1 , preferences for products of the same subgroup become perfectly correlated, so these products are perceived as perfect substitutes. If all $\sigma_{h g}$ go to $\sigma_{g}$, preferences become equally correlated for all products of the same group. The model then reduces to a one-level nested logit model, where the groups constitute the nests. Similarly, if all $\sigma_{g}$ go to 0 , preferences for products of the same group $g$ but a different subgroup become uncorrelated and the model again reduces to a one-level nested logit, where the subgroups now constitute the nests. Finally, as all $\sigma_{h g}$ and $\sigma_{g}$ go to 0 preferences for all products become uncorrelated, and the model reduces to a simple logit model.

At the aggregate demand level, the parameters $\sigma_{h g}$ and $\sigma_{g}$ allow us to assess to which extent competition is localized between products from the same subgroup or group. Note that our specification is more flexible than previous nested logit specifications estimated for the car market. We allow the heterogeneity parameters to differ for different subgroups and groups. Hence, it is possible to assess whether the preferences are more correlated across products from certain (sub)groups than others.

The nested logit model can be interpreted as a special case of the random coefficients models estimated by Berry, Levinsohn and Pakes (1995), Nevo (2001), Petrin (2002) and others. Its main advantage is its econometric tractability, but it is potentially restrictive; see Berry (1994) and Berry and Pakes (2001) for a careful economic discussion. A first restriction is that the nested logit random coefficients only refer to discretely measured features or 
dummy variables ("style", "prestige"), and not to continuously measured features, such as performance or size. Note that these dummy variables are potentially important in the case of cars. They may also at least partially proxy for the omitted continuous features ("size"), especially since we allow the random coefficients to differ by subgroup and group in contrast to previous empirical work. A second and potentially more important restriction relates to the specific distributional assumptions that are imposed on the nested logit random coefficients. These may in principle be relaxed by considering other versions of McFadden's (1978) GEV model. Bresnahan, Stern and Trajtenberg (1997) propose and estimate a GEV model with overlapping groups, but Goldberg and Verboven (2001) do not find support for this model for the car market. Small (1987) proposes an ordered logit model; a worthwhile extension would be a model in which the groups rather than the products are ordered, so that cars from the neighboring segments (e.g. subcompact and compact) are closer substitutes than cars from more distant segments.

\subsection{Oligopoly pricing before liberalization}

To measure the marginal costs for each product $j$, we now specify oligopoly pricing before liberalization. As already reflected in the demand specification, there is no international intrabrand competition (no cross-border trade) because of the combined impact of selectivity and exclusivity. National intrabrand competition, however, may or may not be present, depending on whether the vertical restraints have bite within a country. To incorporate the extent of national intrabrand competition, we explicitly model the manufacturer-retailer relationship.

There are $F$ multi-product manufacturing firms. Each firm $f$ sells a subset $F_{f}$ of the $J$ products. These subsets $F_{f}$ are mutually exclusive, so each product is sold by only one firm. Each firm sells its products through a retailer, rather than directly to consumers. There are $R$ retailers, each retailer $r$ sells a subset $R_{r}$ of the products. There are two stages. In the first stage each manufacturing firm $f$ simultaneously chooses the wholesale price $w_{j}$ for every product $j \in F_{f}$. In the second stage, each retailer $r$ simultaneously chooses the retail price $p_{j}$ for every product $j \in R_{r}$, given the wholesale prices charged by the firms in first stage. The equilibrium is solved by backward induction.

In the second stage, each retailer $r$ simultaneously chooses its prices and obtains the following profits as a function of the $J \times 1$ price vector $p$ :

$$
\Pi_{r}(p)=\sum_{j \in R_{r}}\left(p_{j}-w_{j}\right) s_{j}(p) L
$$


Note that we have normalized the retailer's marginal cost of selling to zero (see more below). We do not yet specify actual retail pricing behavior in the second stage here. At a general level, the $J \times 1$ second-stage equilibrium retail price vector $p$ depends on the $J \times 1$ first-stage wholesale price vector $w$, i.e.

$$
p=p(w)
$$

where $p(\cdot)$ is a $J \times 1$ vector of functions, and a typical function $p_{j}(\cdot)$ describes product $j$ 's retail price as a function of the wholesale price vector $w$. Let $\nabla_{w} p(w) \equiv \partial p(w) / \partial w^{\prime}$ be the $J \times J$ Jacobian matrix of first derivatives. A typical element $(j, k)$ of this matrix contains the effect of an increase in the wholesale price $w_{k}$ on the retail price $p_{j}$. In other words, $\nabla_{w} p(w)$ is the matrix of pass-through rates.

In the first stage, each manufacturer $f$ simultaneously chooses its wholesale prices to maximize its own profits, taking into account the retailers' pricing responses in the second stage through the pass-through function $p(\cdot)$. Each manufacturer $f$ obtains the following profits as a function of the wholesale price vector $w$ :

$$
\Pi_{f}(w)=\sum_{j \in F_{f}}\left(w_{j}-m c_{j}\right) s_{j}(p(w)) L
$$

where $m c_{j}$ is the marginal cost of product $j$. Since the retailer's marginal cost has been normalized to zero, $m c_{j}$ ought to be interpreted as including both the manufacturer's and the retailer's marginal cost. The profit-maximizing wholesale price of each product $j=1, \ldots, J$ should then satisfy the following first-order condition:

$$
s_{j}(p(w))+\sum_{k \in F_{f}}\left(w_{k}-m c_{k}\right)\left(\frac{\partial s_{k}(p)}{\partial p_{1}} \frac{\partial p_{1}(w)}{\partial w_{j}}+\ldots+\frac{\partial s_{k}(p)}{\partial p_{J}} \frac{\partial p_{J}(w)}{\partial w_{j}}\right)=0
$$

A unit increase in product $j$ 's wholesale price $w_{j}$ has two effects. First, it raises the manufacturer's margin so that the profits raise proportional to product $j$ 's market share. Second, it induces positive price responses by the retailers, which indirectly reduces sales.

To write this system of $J$ first-order conditions in vector notation, define the $J \times J$ matrix $\theta^{F}$ as the manufacturing firm's product ownership matrix with a typical element $\theta^{F}(j, k)$ equal to 1 if products $j$ and $k$ are produced by the same firm, and 0 otherwise. Let $s(p)$ be the $J \times 1$ market share vector, and $\nabla_{p} s(p) \equiv \partial s(p) / \partial p^{\prime}$ be the corresponding $J \times J$ Jacobian matrix of first derivatives. Let $m c$ be the $J \times 1$ marginal cost vector. Finally, 
use the operator $\bullet$ to denote element-by-element multiplication of two matrices of the same dimension. We have:

$$
s(p(w))+\left(\theta^{F} \bullet\left[\nabla_{p} s(p) \nabla_{w} p(w)\right]^{\prime}\right)(w-m c)=0 .
$$

The solution $(\bar{p}, \bar{w})$ to the second stage system (5) and the first stage system (7) constitutes the subgame perfect equilibrium, which we assume to exist. Inverting the system (7) at this solution, we obtain the following solution for the marginal cost vector:

$$
m c=\bar{w}+\left(\theta^{F} \bullet\left[\nabla_{p} s(\bar{p}) \nabla_{w} p(\bar{w})\right]^{\prime}\right)^{-1} s(\bar{p}) .
$$

To complete the specification, it is necessary to become more explicit about the nature of retail pricing in the second stage, as given by (5), with the corresponding matrix of passthrough rates $\nabla_{w} p(w)$.

\section{Full national intrabrand competition}

This scenario assumes that the current distribution system cannot successfully limit national intrabrand competition. Retailers compete vigorously in the second stage, driving down retail prices to wholesale prices. Such full intrabrand competition may be easily modelled by defining the retailers' product subsets $R_{r}$ in (4) as mutually nonexclusive, such that every product $j$ is owned by at least two retailers $r$ and $r^{\prime}$. Oligopoly pricing then effectively reduces to a traditional model of pricing for the car market, as in Berry, Levinsohn and Pakes (1995).

When at least two retailers compete for the same product $j$, the retail price equilibrium (5) is simply given by $p=w$, and the pass-through matrix $\nabla_{w} p(w)$ reduces to the identity matrix $I_{J}$ (i.e. an increase in the wholesale price of product $j$ leads to the same increase in the retail price of product $j$ and leaves the retail prices of the other products unaffected). At the equilibrium solution $(\bar{p}, \bar{w})$, the marginal cost vector (8) simplifies to:

$$
\begin{aligned}
m c & =\bar{p}+\left(\theta^{F} \bullet\left[\nabla_{p} s(\bar{p})\right]^{\prime}\right)^{-1} s(\bar{p}) \\
& \equiv \widehat{m c}^{F}
\end{aligned}
$$

As in previous work, the marginal cost vector is then simply measured by the observed equilibrium price vector $\bar{p}$ minus the estimated wholesale margin vector $-\left(\theta^{F} \bullet\left[\nabla_{p} s(\bar{p})\right]^{\prime}\right)^{-1} s(\bar{p})$.

\section{Limited national intrabrand competition}


This scenario assumes that distribution system can effectively eliminate or reduce national intrabrand competition. The absence of national intrabrand competition can be modelled by defining the retailers' product subsets $R_{r}$ in (4) as mutually exclusive. Oligopoly pricing then generalizes Rey and Stiglitz' (1995) model in which two manufacturers sell to one retailer who does not compete with other retailers of the same brand.

When each retailer, as the exclusive owner of all products in its product set $R_{r}$, chooses its retail prices to maximize its own retail profit (4), the following first-order conditions should be satisfied for each product $j=1, \ldots, J$ :

$$
s_{j}(p)+\sum_{k \in R_{r}}\left(p_{k}-w_{k}\right) \frac{\partial s_{k}(p)}{\partial p_{j}}=0 .
$$

To write this system of $J$ first-order conditions in vector notation, define the $J \times J$ matrix $\theta^{R}$ as the retailer's product ownership matrix with a typical element $\theta^{R}(j, k)$ equal to 1 if products $j$ and $k$ are sold by the same retailer, and equal to 0 otherwise. We have:

$$
s(p)+\left(\theta^{R} \bullet\left[\nabla_{p} s(p)\right]^{\prime}\right)(p-w)=0 .
$$

We can invert this system to obtain:

$$
f(p, w) \equiv p-w+\left(\theta^{R} \bullet\left[\nabla_{p} s(p)\right]^{\prime}\right)^{-1} s(p)=0 .
$$

Suppose the system $f(p, w)=0$ meets the conditions of the implicit function theorem, i.e. every $f_{j}(\cdot)$ is continuously differentiable with respect to every $p_{j}$ and $w_{j}$, and the Jacobian matrix $\nabla_{p} f(p, w)$ evaluated at the equilibrium solution $(\bar{p}, \bar{w})$ is non-singular. Then the system $f(p, w)=0$ implicitly defines the functions $p(\cdot)$ of the second-stage Nash equilibrium retail price vector at the equilibrium solution $(\bar{p}, \bar{w})$. Furthermore, the matrix of pass-through rates $\nabla_{w} p(\bar{w})$ evaluated at $(\bar{p}, \bar{w})$ is given by:

$$
\begin{aligned}
\nabla_{w} p(\bar{w}) & =-\left[\nabla_{p} f(\bar{p}, \bar{w})\right]^{-1} \nabla_{w} f(\bar{p}, \bar{w}) \\
& =\left[\nabla_{p} f(\bar{p}, \bar{w})\right]^{-1} .
\end{aligned}
$$

where the second equality follows from the fact that $\nabla_{w} f(\bar{p}, \bar{w})$ equals minus the identity matrix. ${ }^{5}$

\footnotetext{
${ }^{5}$ In the numerical analysis, we originally computed $\nabla_{w} p(\bar{p})$ directly from (9) rather than from $f(p, w)$. But the procedure to first inverting the system and then setting $\nabla_{p} f(\bar{p}, \bar{w})$ equal to the identity matrix proved a useful simplification in the numerical analysis.
} 
Rearranging (10), we can write the (to us) unobserved equilibrium wholesale price vector as a function of the observed equilibrium retail price vector:

$$
\bar{w}=\bar{p}+\left(\theta^{R} \bullet\left[\nabla_{p} s(\bar{p})\right]^{\prime}\right)^{-1} s(\bar{p}) .
$$

i.e. the wholesale price vector equals the retail price vector minus the retail margin vector $-\left(\theta^{R} \bullet \nabla_{p} s(\bar{p})\right)^{\prime-1} s(\bar{p})$. After substituting out (11) and (12), the marginal cost vector (8) becomes:

$$
\begin{aligned}
m c & =\bar{p}+\left(\theta^{R} \bullet\left[\nabla_{p} s(\bar{p})\right]^{\prime}\right)^{-1} s(\bar{p})+\left(\theta^{F} \bullet\left[\nabla_{p} s(\bar{p})\left(\nabla_{p} f(\bar{p}, \bar{w})^{-1}\right)\right]^{\prime}\right)^{-1} s(\bar{p}) \\
& \equiv \widehat{m c}^{N}
\end{aligned}
$$

Intuitively, the marginal cost vector can be measured by the observed equilibrium retail price vector minus the estimated retail margin vector $-\left(\theta^{R} \bullet\left[\nabla_{p} s(\bar{p})\right]^{\prime}\right)^{-1} s(\bar{p})$ minus the estimated wholesale margin vector $-\left(\theta^{F} \bullet\left[\nabla_{p} s(\bar{p})\left(\nabla_{p} f(\bar{p}, \bar{w})^{-1}\right)\right]^{\prime}\right)^{-1} s(\bar{p})$.

To summarize, we measure the marginal cost vector for all products $j$, based on two alternative scenarios of retail pricing before liberalization. In the first scenario, there is full national intrabrand competition, so that retail margins are zero. In the second scenario, there is no intrabrand competition so that the retail margin vector is given by $-\left(\theta^{R} \bullet \nabla_{p} s(\bar{p})\right)^{\prime-1} s(\bar{p})$ in (12). In practice, we have outside information (from the European Commission) on the average percentage retail margin $\sum_{j=1}^{J}\left(p_{j}-w_{j}\right) / J$ in the various countries. These numbers are greater than zero but lower than the average as calculated using (12), suggesting that a situation of "limited" intrabrand competition is the more realistic scenario. We consider such a situation by modifying (12) to:

$$
\bar{w}=\bar{p}+\lambda\left(\theta^{R} \bullet\left[\nabla_{p} s(\bar{p})\right]^{\prime}\right)^{-1} s(\bar{p}) .
$$

where the parameter $\lambda$ is chosen such that the average percentage retail margin in (13) equals the average obtained from our outside source. We correspondingly modify $\nabla_{w} p(\bar{w})$ to compute the marginal cost vector.

\subsection{Oligopoly pricing after liberalization}

The liberalization of the distribution system has two main effects. First, it creates national intrabrand competition, at least to the extent that this did not already exist before liberalization. Second, it creates international intrabrand competition, which may be modelled 
in different ways. A first approach directly introduces cross-border arbitrage costs in the consumers' indirect utility. The creation of international competition then amounts to a reduction in the consumers' arbitrage costs (from the initially prohibitive levels). We do not follow this approach since the liberalization does not directly affect consumers' obstacles to trade; final consumers in fact already have unrestricted trade opportunities before liberalization and they simply do not seem to take advantage of them.

A second approach to modelling international intrabrand competition extends the model of oligopoly pricing by including constraints on international price or markup differentials. We follow this approach since it has the direct interpretation of capturing arbitrage interventions by either the independent resellers or the authorized dealers' foreign branches. The most straightforward way would be to introduce a constraint on international price differentials, the interpretation being that arbitrage intervention will take place whenever the price differentials exceed cross-border trade costs, such as transportation, administration and delay costs. In practice, however, it is important to account for the fact that the products for which prices are measured are not completely identical across countries. They may differ across countries because of specification differences, such as horsepower, better optional equipment, the right-hand drive regulation in the U.K., etc... Arbitrage intervention will therefore only take place when the price differentials exceed the cross-border trade costs after adjusting for any differences in the marginal costs. Put differently, it is appropriate to introduce the constraints on international markup differentials rather than on international price differentials. $^{6}$

We can now specify oligopoly pricing with constraints on international markup differentials. To simplify, we assume there is full national intrabrand competition after liberalization, so that wholesale and retail prices coincide, i.e. $w=p$. It is necessary to reintroduce our subscript notation: there are $M$ national markets, $m=1, \ldots, M$. Both cost and demand conditions are independent of the prices in the other markets. Marginal cost is independent of foreign prices because there are constant marginal costs. Demand is independent of price because consumers' arbitrage costs are prohibitive, so the $L_{m}$ consumers in market $m$ effectively base their choices only on the models available in market $m$. Interdependence between markets stems from the inequality constraint that for each product $j$ and each pair of countries $m$ and $n$ the markup differential should be less than a percentage $\tau$, i.e.

\footnotetext{
${ }^{6} \mathrm{~A}$ case may be made to consider constraint on price differentials so as to capture the effects of direct regulation, e.g. the up to now never enforced rule that price differentials should not exceed $12 \%$ on a permanent basis. See Davidson, Dewatripont, Ginsburgh, and Labbé (1989) for a theoretical analysis in a duopoly setting. There approach is consistent with ours since they assume that the marginal costs are identical across countries.
} 
$p_{j m}-\widehat{m c}_{j m} \leq(1+\tau)\left(p_{j n}-\widehat{m c}_{j n}\right)$, where $\widehat{m c}_{j m}$ is the marginal cost of product $j$ in market $m$ as computed from solving the equilibrium before liberalization (i.e. it refers to either $\widehat{m c}_{j m}^{N}$ or $\widehat{m c}_{j m}^{F}$ ). The parameter $\tau$ can take alternative values and is our measure of the extent of international intrabrand competition after liberalization. Each firm $f$ maximizes its total profits across all markets, subject to a set of inequality constraints on the prices of every product $j$ and every pair of countries $m$ and $n$ :

$$
\begin{gathered}
\Pi_{f m}\left(p_{m}\right)=\sum_{m=1}^{M} \sum_{j \in F_{f m}}\left(p_{j m}-\widehat{m c}_{j m}\right) s_{j m}\left(p_{m}\right) L_{m} \\
\text { subject to } \quad \begin{array}{c}
(1+\tau)\left(p_{j n}-\widehat{m c}_{j n}\right)-\left(p_{j m}-\widehat{m c}_{j m}\right) \geq 0 \\
j=1, \ldots, J, \quad m, n=1, \ldots, M .
\end{array}
\end{gathered}
$$

Define Lagrange multipliers $\lambda_{j m n}$ associated with the constraints of each product $j$ and each pair of countries $m$ and $n$. The constrained profit-maximizing prices of product $j$ in markets $m=1, \ldots, M$ should satisfy the following Kuhn-Tucker conditions:

$$
\begin{gathered}
\left(s_{j m}\left(p_{m}\right)+\sum_{k \in F_{f m}}\left(p_{k m}-\widehat{m c}_{k m}\right) \frac{\partial s_{k m}\left(p_{m}\right)}{\partial p_{j m}}\right) L_{m}-\sum_{n=1}^{M} \lambda_{j m n}+(1+\tau) \sum_{n=1}^{M} \lambda_{j n m}=0 \\
(1+\tau)\left(p_{j n}-\widehat{m c}_{j n}\right)-\left(p_{j m}-\widehat{m c}_{j m}\right) \geq 0, \quad \lambda_{j m n} \geq 0 \\
\lambda_{j m n}\left((1+\tau)\left(p_{j n}-\widehat{m c}_{j n}\right)-\left(p_{j m}-\widehat{m c}_{j m}\right)\right)=0, \\
m, n=1, \ldots, M .
\end{gathered}
$$

The first-order conditions with respect to prices (in the first row of (15)) generalize our previous unconstrained first-order conditions (now with a subscript $m$ ), extended with a set of nonnegative Lagrange multipliers. The complementary slackness conditions (in the second and third row) state that for each pair of countries $m$ and $n$ the constraint is either binding ("active"), or nonbinding in which case $\lambda_{j m n}=0$. Although there are many country pair combinations, several constraints can be eliminated. The constraints are obviously nonbinding for $m=n$, so that $\lambda_{j m m}=0$ for all $m$. The constraints of country pair $(m, n)$ and $(n, m)$ are mutually exclusive, so least $\lambda_{j m n}=0$ or $\lambda_{j n m}=0$. Similarly, if the constraint of country pair $(m, n)$ and $\left(m, n^{\prime}\right)$ are both binding, then $p_{j n}=p_{j n^{\prime}}$ so that the constraints of both country pairs $\left(n, n^{\prime}\right)$ and $\left(n^{\prime}, n\right)$ must be nonbinding, so $\lambda_{j n n^{\prime}}=\lambda_{j n^{\prime} n}=0$. By eliminating these possibilities, one can easily verify that product $j$ has at most $M-1$ active constraints, hence $\lambda_{j m n}>0$ for at most $M-1$ country pairs. 
A Nash equilibrium is a $J M \times 1$ price vector $p^{*}$ such that the Kuhn-Tucker conditions (15) are satisfied for all products $j$. To compute a candidate Nash equilibrium we proceed as follows. For each product $j$, we impose a set of $K_{j} \leq M-1$ active constraints (such that none of them are mutually exclusive or inconsistent otherwise). In addition, for each product $j$ we impose the $M$ first-order conditions with respect to prices, setting the Lagrange multipliers of the nonactive constraints equal to zero. We simplify these $M$ first-order conditions to a reduced system of $M-K_{j}$ equations by substituting out the $K_{j}$ nonzero $\lambda_{j m n}$. For each product $j$, we thus impose $K_{j}$ active constraints and $M-K_{j}$ other equations as obtained from the first-order conditions. The candidate Nash equilibrium is the solution to this system of equations over all products $j$. The Appendix works out an example of such a system of equations, in which only the constraint of one product $j$ for one country pair $(1,2)$ is binding (so $K_{j}=1$ for product $j$ and $K_{j}=0$ otherwise).

Once the solution of a candidate Nash equilibrium is obtained, we check whether all the Kuhn-Tucker conditions are satisfied, in particular whether (i) no active constraint is unjustified, i.e. $\lambda_{j m n} \geq 0$ for all $j, m, n$, and whether (ii) no inactive constraint is violated. If all the conditions are satisfied, we use the solution as our constrained Nash equilibrium. If not, then we consider a new candidate Nash equilibrium, by relaxing one or more of the active constraints and/or imposing one or more new constraints, until a solution is found that satisfies all the Kuhn-Tucker conditions. This is a process of trial and error, common in constrained optimization problems. In practice, we proceed as follows. We begin by imposing all the constraints that are violated under the old equilibrium, and compute the candidate Nash equilibrium. We then check whether new constraints need to be imposed and whether some constraints need to be relaxed, and, if so, we compute a new candidate Nash equilibrium. We usually need about 5 to 10 trials before we obtain a solution that satisfies all the Kuhn-Tucker conditions. Note that, if we set $\tau=0$, the problem is simplified. In this case, the problem reduces to a simple constrained maximization problem with equality constraints only, i.e. $\left(p_{j n}-\widehat{m c}_{j n}\right)-\left(p_{j m}-\widehat{m c}_{j m}\right)=0$ for all $j, m$ and $n$.

\subsection{Welfare}

To compare the computed equilibrium prices $p^{*}$ after liberalization with the observed equilibrium prices $\bar{p}$ before liberalization, we compute the changes in the various welfare components, in particular consumer surplus and producer surplus. Define consumer surplus as the expected value of the maximum of the utilities (1). Using the nested logit distributional assumptions, the change in consumer surplus in market $m$ is equal to: 


$$
\Delta C S_{m}=\frac{I\left(p_{m}^{*}\right)}{\alpha_{m}}-\frac{I\left(\bar{p}_{m}\right)}{\alpha_{m}},
$$

where $I$ is the inclusive value defined by (3), now written as a function of the price vectors before or after liberalization. For comparison purposes, we also compute the changes in the price indices, using either the pre-liberalization or the post-liberalization market shares as weights. The change in industry profits is simply given by

$$
\Delta P S_{m}=\sum_{f=1}^{F} \Pi_{f m}\left(p_{m}^{*}\right)-\sum_{f=1}^{F} \Pi_{f m}\left(\bar{p}_{m}\right) .
$$

The exogenous variables are assumed not to change after liberalization. In particular, the exogenous part of utility in (1), i.e. $x_{j}^{\prime} \beta+\xi_{j}$, and marginal cost, $\widehat{m c}_{j}$ remain unchanged for all products $j$. Our focus is thus entirely on a quantification of the allocative effects of liberalizing the distribution system. A more complete analysis would also incorporate the efficiency effects, which may enter through changes utility, marginal costs or fixed costs.

\section{Data and estimation}

\subsection{The data}

The data set consists of prices, sales and physical characteristics of (essentially) all cars sold in five European markets during 1970-1999. The included countries are Belgium, France, Germany, Italy and the United Kingdom. Since approximately 80 models are sold in every market/year, the total number of observations is about 12,000 . The price data are pre-tax and post-tax list prices corresponding to the base model available in the market, as available in consumer catalogues. Sales are new car registrations for the model range. Physical characteristics (also from consumer catalogues) include dimensions (weight, length, width, height), engine characteristics (horsepower, displacement) and performance measures (speed, acceleration and fuel efficiency). The data set also includes variables to identify the model, the brand, the firm, the country of origin/production location, and the market segment ("class"). The data set is augmented with macro-economic variables including population, exchange rates, GDP and consumer price indices for the various markets over the relevant period. Finally, there is information on dealer discounts and gross dealer margins for a selected number of models/years. A more detailed description of the data set and the sources, for the shorter period of 1980-1993, is provided in Goldberg and Verboven (2001). 


\subsection{Demand estimation and identification}

We estimate the nested logit demand system (2), where the mean valuation $\delta_{j}$ is given by (1). The unobserved part of the mean valuation, $\xi_{j}$, is the error term and enters nonlinearly in (2). Following Berry's (1994) nested logit example, we transform the demand system to obtain a linear expression for $\xi_{j}$; see Verboven (1996) for details on the derivation for the two-level nested logit. Adding a market subscript $m$ and a time subscript $t$, the estimating demand equation takes the following form:

$$
\ln \left(s_{j m t} / s_{0 m t}\right)=x_{j m t}^{\prime} \beta-\left(\alpha / y_{m t}\right) p_{j m t}+\sigma_{h g} \ln \left(\bar{s}_{j / h g m t}\right)+\sigma_{g} \ln \left(\bar{s}_{h / g m t}\right)+\xi_{j}+\xi_{m t}+\xi_{j m t},
$$

where $\bar{s}_{j / h g m t}$ is the market share of product $j$ in its subgroup $h$ of $g$, and $\bar{s}_{h / g m t}$ is the market share of all products of subgroup $h$ in group $g$. The price coefficient $\alpha$ is interacted with the inverse of income, $y_{m t} .{ }^{7}$ The product fixed effects $\xi_{j}$ control for unobserved mean product valuations that do not vary over time or across markets, e.g. style or image. Similarly, the full set of market/time fixed effects $\xi_{m t}$ captures preferences for cars relative to the outside good, and can thus be thought of as accounting for macro-economic fluctuations that affect the decision to purchase a new car. Finally, the error term $\xi_{j m t}$ captures the remaining unobserved product valuations varying across products, markets and time, e.g. due to unobserved variations in advertizing, delivery times, etc.

To estimate the model, the main identification assumption is that the product characteristics entering $x_{j m t}$ are predetermined and thus uncorrelated with the error term $\xi_{j m t}$. The price $p_{j m t}$ and the market shares $\ln \left(\bar{s}_{j / h g m t}\right)$ and $\ln \left(\bar{s}_{h / g m t}\right)$ may however be correlated with the error term. This follows from the fact that the manufacturers may take into account all the relevant demand factors when setting their prices, including the (to the econometrician) unobserved error terms. Ordinary least squares will therefore produce biased estimates and instrumental variables should be used; in our application, we use a fixed effects two-stage least squares estimator. Supply side variables are the obvious candidates for instruments in addition to $x_{j m t}$. Cost shifters are however not readily available at the detailed product level. Following Berry, Levinsohn and Pakes (1995) and much of the subsequent literature, we instead use markup shifters as additional instruments.

Their starting point is that firm $f$ 's pricing policy for product $j$ does not only depend

\footnotetext{
${ }^{7}$ Nevo (2001) also interacts $\alpha$ with income (allowing $\alpha$ to vary across individuals). He interacts $\alpha$ with income and income squared, whereas we interact it with the inverse of income. If price is small relative to (capitalized) income, our specification in fact also approximates the familiar Cobb Douglass specification in which price enters through the term $\alpha \ln \left(y-p_{j}\right)$.
} 
on product $j$ 's own characteristics $x_{j m t}$. Because of oligopolistic interdependence, it also depends on the characteristics of the other products owned by firm $f$ and on the characteristics of the competing products (measuring their closeness in the product space). Berry, Levinsohn and Pakes propose to use functions of the competitors' characteristics as instruments, and discuss the general problem of how to choose approximately efficient instruments. In the spirit of their results, we adopted the following list of instruments, making use of the specific structure of the nested logit model: (i) the products' own observed characteristics

$x_{j m t}$; (ii) the number of products, and the sums of characteristics of other products of the same firm belonging to the same subgroup, interacted with a subgroup dummy variable; (iii) the number of products, and the sums of the characteristics of competing products belonging to the same subgroup, interacted with a subgroup dummy variable; (iv) the number of products, and the sums of the characteristics of competing products belonging to the same group, interacted with a group dummy variable. Note that we interact the "oligopolistic interdependence" instruments in (ii)-(iv) with subgroup or group dummy variables, since we allow the differentiation parameters $\sigma_{h g}$ and $\sigma_{g}$ to differ across subgroups and groups.

\subsection{Demand estimates}

The parameter estimates are presented in Table 2. For comparison purposes, the first column presents the results from a restricted specification in which $\sigma_{h g}$ is equal for all ten subgroups and $\sigma_{g}$ is equal across all five groups. This is the commonly estimated version of the nested logit model. The second column presents the results of a more flexible specification, in which the subgroup segmentation parameters are allowed to vary by segment. To check for the sensitivity of the results, we also considered various alternative specifications. For example, we estimated a restricted specification in which $\xi_{m t}=\xi_{m}+\xi_{t}$. We also allowed some of the parameters to vary across countries, and we estimated the model for two separate subperiods: 1970-1984 and 1985-1999. Most parameter estimates were robust across specifications.

Both specifications in Table 2 show that the parameters of the included characteristics are of the expected sign and significant. Horsepower, width and height positively affect the consumers' mean valuation, whereas fuel inefficiency (measured as liters per $100 \mathrm{~km}$ ) has a negative impact. Similarly, price has a significantly negative effect. The joint significance of the fixed effects $\xi_{j}$ and $\xi_{m t}$ could not be rejected at a very high significance level ( $P$-value less than .0001).

The foreign firm effect is negative and significant, so the domestic incumbents face a competitive advantage over their foreign competitors in terms of the mean consumer valuation (e.g. Peugeot/Citroën and Renault in France; Volkswagen, etc. in Germany; Fiat in Italy). 
We also considered two specifications to look whether the foreign firm effect has changed over time. A first specification added a foreign firm effect interacted with a dummy variable for the post-1984 period; as second specification added a foreign firm effect interacted with a time trend. Both specifications show that the importance of the foreign firm effect has declined substantially, by some $40 \%$ over a fifteen year period. This indicates that the competitive advantage of the domestic incumbents is declining, probably due to the process of European integration (as most foreign firms are E.U. firms, or have production facilities in the E.U.).

Now consider the segmentation parameters $\sigma$. For both the restricted and the unrestricted specification the restrictions implied by the random utility maximization assumption are satisfied for all parameters, i.e. $1 \geq \sigma_{h g} \geq \sigma_{g} \geq 0$. The restricted specification shows that consumer preferences are significantly more correlated for cars within the same subgroup (parameter of .706), than for cars within the same group but a different subgroup (parameter of .502). Put differently, consumers have more homogeneous valuations regarding cars that come from both the same origin (domestic or foreign) and the same segment than regarding cars that only come from the same segment. Furthermore, preferences are more correlated for cars of the same segment than for cars of different segments (since .502 is significantly different from 0 ). These results are roughly in line with previous estimates for the European car market, in particular by Goldberg and Verboven (2001).

The flexible specification allows the segmentation parameters $\sigma_{h g}$ and $\sigma_{g}$ to vary by subgroup and group. To reduce the number of segmentation parameters to be estimated, we constrained $\sigma_{D g}=\sigma_{F g}$ (where $D$ denotes domestic and $F$ denotes foreign), i.e. the degree of heterogeneity within a domestic subgroup is the same that within a foreign subgroup of a given group $g$. This specification reveals several interesting new insights. Consider first the parameters for the subgroups $\left(\sigma_{h g}\right)$, defined by cars of both the same origin and segment. The estimates show that consumers are typically more homogeneous regarding cars from the smaller segments than regarding cars from the larger ones. For example, preference correlation is .849 for domestic subcompact cars, and only .461 for domestic luxury cars. This finding appears consistent with our a priori guess that the degree of differentiation increases as one moves up to the more expensive segments. The only exception to this pattern is the standard segment, for which the segmentation parameter is close to that of the subcompact segment.

Considering the parameters from the groups $\left(\sigma_{g}\right)$, one can see that $\sigma_{h g}>\sigma_{g}$ in all cases: consumers thus perceive cars from the same origin as significantly closer substitutes than cars from a different origin. Put differently, for each segment we find significant additional segmentation between domestic and foreign cars. Note that the group segmentation pa- 
rameters also suggest that the degree of heterogeneity increases as one moves to the more expensive segments (compare e.g. the estimate of .410 for the subcompact versus .171 for the luxury), but the pattern is weaker than for the subgroup segmentation parameters.

Table 2. Parameter estimates for the nested logit demand*

\begin{tabular}{|c|c|c|}
\hline & restricted & flexible \\
\hline \multicolumn{3}{|c|}{ Mean valuation parameters } \\
\hline constant & $-8.760 \quad(.554)$ & $-8.059 \quad(.504)$ \\
\hline horsepower & $.011 \quad(.002)$ & $(.001)$ \\
\hline fuel inefficiency & $-.052 \quad(.007)$ & $(.006)$ \\
\hline width & $(.002)$ & $(.002)$ \\
\hline height & $(.003)$ & $(.002)$ \\
\hline foreign & $-.784 \quad(.038)$ & $(.033)$ \\
\hline- price $(\alpha)$ & $2.281 \quad(.204)$ & $(.111)$ \\
\hline \multicolumn{3}{|c|}{ Subgroup segmentation parameters $\left(\sigma_{h g}\right)$} \\
\hline subcompact & $.706 \quad(.022)$ & $(.020)$ \\
\hline compact & same & $(.024)$ \\
\hline intermediate & same & $(.026)$ \\
\hline standard & same & $(.022)$ \\
\hline luxury & same & $(.043)$ \\
\hline \multicolumn{3}{|c|}{ Group segmentation parameters $\left(\sigma_{g}\right)$} \\
\hline subcompact & $.502 \quad(.022)$ & $(.029)$ \\
\hline compact & same & $(.032)$ \\
\hline intermediate & same & $(.034)$ \\
\hline standard & same & $(.028)$ \\
\hline luxury & same & $(.048)$ \\
\hline
\end{tabular}

${ }^{*}$ The number of observations is 12077. Standard errors are in parentheses. Fixed effects $\xi_{j}$ and $\xi_{m t}$ are included.

It is instructive to look at the substitution patterns implied by the demand estimates, and see how they differ between the restricted and the unrestricted nested logit specifications. Table 3 provides a summary, presenting the average own- and cross-price elasticities. The average elasticities for the whole market are in line with previous work, for example Goldberg and Verboven's (2001) findings. Interesting new findings arise when comparing the price elasticities for the different segments between the restricted and the restricted specification. The restricted specification shows that the own-elasticities are increasing as one moves to 
higher segments. The average elasticity in the luxury segment is more than three times the average elasticity in the subcompact segment. The increasing pattern follows from the near proportional relationship between the price elasticities and the price level as implied by the restricted nested logit: the average price level in the luxury segment is also more than three times higher than the average price level in the subcompact segment. To put this in a different way, in the restricted nested logit the semi-elasticities (elasticities divided by the price) do not show systematic variation across different segments. The flexible nested logit shows that the own-price elasticities no longer move proportionally to price as one moves up to the more expensive segments. For example, the average own-price elasticity in the subcompact and the luxury segment are more or less the same (4.7). As a result, the semielasticities tend to be lower for the more expensive models (the exception being the standard segment). The reason for these differences with the restricted nested logit is our earlier finding that consumers perceive products in the inexpensive segments as closer substitutes to each other than products in the more expensive segments. Note that similar remarks can be made regarding the pattern of cross-price elasticities across different segments. In fact, the restricted specification shows an even sharper rising pattern for the cross-price elasticities between cars of the same subgroup or group.

Table 3 also summarizes the price elasticities by origin, domestic or foreign. Both the restricted and the flexible specification show that the own-price elasticity of domestic cars is lower on average that the own-price elasticity of foreign cars. 
Table 3. Substitution patterns (in 1999)

\begin{tabular}{l|c|ccc}
\hline & Own elasticity & \multicolumn{3}{c}{$\begin{array}{c}\text { Cross elasticities with respect to car from } \\
\text { same subgroup }\end{array}$} \\
\multicolumn{5}{|c}{ same group } \\
different group \\
\hline \multicolumn{5}{l}{ Averages for restricted specification } \\
\hline all & 5.549 & .338 & .103 & .002 \\
\hline subcompact & 3.177 & .123 & .037 & .002 \\
compact & 4.518 & .238 & .070 & .003 \\
intermediate & 5.797 & .275 & .080 & .002 \\
standard & 8.004 & .608 & .172 & .002 \\
luxury & 10.781 & .965 & .331 & .003 \\
\hline foreign & 5.871 & .250 & .077 & .001 \\
domestic & 4.925 & .510 & .154 & .004 \\
\hline Averages for flexible specification & & & \\
\hline all & 4.778 & .295 & .059 & .002 \\
\hline subcompact & 4.743 & .259 & .019 & .002 \\
compact & 3.589 & .179 & .070 & .003 \\
intermediate & 3.670 & .156 & .047 & .002 \\
standard & 8.684 & .801 & .151 & .001 \\
luxury & 4.715 & .285 & .053 & .002 \\
\hline foreign & 5.032 & .208 & .041 & .001 \\
domestic & 4.286 & .464 & .093 & .003 \\
\hline \multicolumn{5}{l}{}
\end{tabular}

\subsection{Marginal costs}

Based on the demand estimates and the specification of oligopoly pricing before liberalization it is possible to recover the marginal costs. Recall that we considered two alternative pricing scenarios, one with full intrabrand competition within a country and one with limited intrabrand competition within a country. In both scenarios the manufacturing firms behave non-cooperatively, maximizing the sum of the profits of all products in their portfolio, as reflected by the firms' product ownership matrix $\theta^{F}$. The first and third column of Table 4 show the 1999 averages of the marginal costs implied by the two pricing models (flexible demand specification). The estimates generally appear plausible and in line with previous estimates obtained in the literature; the implied Lerner indices are in the range of 20-40\%. A comparison across products further conforms to intuition and previous research. For example, domestic cars on average obtain higher margins than foreign cars. The pattern of margins across segments is closely related to the pattern of the own price elasticities 
discussed before.

Comparing the averages across countries, there are sometimes substantial differences. In particular, the marginal cost of cars sold in the U.K. appears substantially higher than the marginal cost of cars in the other countries. This finding is similar to Goldberg and Verboven (2001), who analyzed it in detail. One explanation for the higher marginal costs in the U.K. is the presence of extra unmeasured optional equipment, such as radio or insurance. Furthermore, the importance of local distribution costs, which may amount to up to up $35 \%$ of the price of a car, may explain the higher marginal costs during periods when the local exchange is overvalued. In fact, in 1999 the pound had appreciated by about $30 \%$ compared to 1997 , without an accompanying reduction in relative factor prices. Distribution costs are therefore (temporarily) higher in the U.K. than elsewhere. Despite these explanations, the estimated marginal costs in the U.K. appear rather high compared to the other countries, as also pointed out by Goldberg and Verboven.

An alternative explanation is the presence of collusion in the U.K., so that the markups are underestimated and the marginal costs are overestimated when non-cooperative behavior is imposed. This possibility cannot be ruled out in light of the repeated investigations by the U.K. Competition Commission. Goldberg and Verboven considered the possibility of collusion, by modifying the firms' product ownership matrix $\theta^{F}$ for the U.K. market, such that firms behave as maximizing the sum of profits over all products of the same subsegment. We here take a somewhat more systematic approach. For every country except the reference country Belgium we modify $\theta^{F}$ as follows. We replace the zeros (denoting competing products) on each row $j$ in $\theta^{F}$ by a parameter $\phi_{j}$, which is chosen in such a way that the marginal cost for product $j$ equals the marginal cost for the same product $j$ in Belgium. One may interpret the parameter $\phi_{j}$ as a "conjectural variation" parameter, capturing deviations from the non-cooperative pricing assumption relative to Belgium. A positive $\phi_{j}$ (less than 1) means that the price of product $j$ is determined with a partial account for the effect on competing products (not in the firm's own portfolio), hence the product is set less in a partially collusive way. In the extreme case where $\phi_{j}$ is equal to 1 , product $j$ is priced fully collusively, i.e. as if the effect on the other products' profits is fully taken into account. Conversely, a negative $\phi_{j}$ would mean that the price of a product is set below the multi-product non-cooperative price. Constructing the conjectural variations this way, we find that the pricing in France, Germany and Italy appears slightly less competitive than multi-product non-cooperative pricing, relative to Belgium, with average estimates of $\phi_{j}$ in the range of 0.18-0.25 under full intrabrand competition and 0.09-0.22 under limited intrabrand competition, see Table 4. In the U.K. pricing appears to be quite collusive, with an average conjectural variation estimate of around 0.8 . 
In the simulation analysis below we do not take a position on whether marginal costs differ across countries (as implied by non-cooperative pricing) or whether conduct differs (as under the constructed conjectural variations). We simply report and discuss the results based on both extremes, realizing that the truth may lie somewhere in the middle.

Table 4. Marginal cost estimates and $\phi$ (in 1999)

\begin{tabular}{l|cc|cc}
\hline & \multicolumn{2}{|c|}{ Full intrabrand competition } & \multicolumn{2}{c}{ Limited intrabrand competition } \\
\hline & marginal cost & implied $\phi$ & marginal cost & implied $\phi$ \\
\hline Belgium & 11164 & 0.00 & 10330 & 0.00 \\
France & 12124 & 0.18 & 11015 & 0.10 \\
Germany & 11562 & 0.22 & 10304 & 0.09 \\
Italy & 12878 & 0.25 & 12045 & 0.22 \\
U.K. & 16686 & 0.83 & 15559 & 0.81 \\
Note: Marginal costs are expressed in Euro.
\end{tabular}

\section{The effects of liberalization}

We begin the analysis by assuming that full national intrabrand competition already exists before liberalization, so the current system does not effectively limit intrabrand competition within a country. This allows us to first focus purely on the effects of increased international intrabrand competition, or cross-border trade. Next we extend the analysis by considering the possibility of limited national intrabrand competition before liberalization. This enables us to evaluate the cumulative effect from introducing international and national intrabrand competition after liberalization.

Our simulation analysis amounts to numerically computing the new Nash equilibrium after imposing constraints on international markup differentials, based on the estimates obtained for the demand and marginal cost parameters (flexible demand specification). We consider constraints on markup differentials of 12 percent and 0 percent, to capture the effects of intermediate and strong increased cross-border trade. The $12 \%$ number is obviously arbitrary. We extensively experimented with alternative percentage constraints on markup differentials, but there are no essential new insights from reporting these results as well.

\subsection{Full national intrabrand competition before liberalization}

Under full national intrabrand competition before liberalization, the impact of liberalization amounts to a reduction in the degree of international price discrimination. Recent theo- 
retical work has shown that it is difficult to draw general conclusions regarding the price, profit and welfare effects of eliminating third-degree price discrimination in an oligopolistic setting; for a survey, see Stole (2001). Under monopoly, the elimination of price discrimination typically leads to a price in between the discriminatory prices, to reduced profits and ambiguous welfare effects. Things are quite different under oligopoly. The elimination of price discrimination may sometimes lead to prices that are below all the discriminatory prices; see Thisse and Vives' (1988) location model, and Corts' (1998) model with "all-out competition". Furthermore, eliminating price discrimination may sometimes raise the firms' profits; see Holmes (1989), but also see Armstrong and Vickers (2001) for a model where the elimination of price discrimination reduces profits when competition becomes sufficiently intense. Finally, the welfare effects are even more difficult to predict than under monopoly. The reason why price, profit and welfare effects are more difficult to sign ex ante under oligopoly is the presence of a business-stealing effect in addition to the individual profit enhancement effect. Fortunately, an empirical analysis can still evaluate the effects from reducing or eliminating price discrimination.

First consider the price effects from introducing a $12 \%$ or a $0 \%$ constraint on international markup differentials. For each car, we find that there is at least one country where the price would fall and at least one country where the price would rise after liberalization. Hence, there are no situations of "all-out competition" where all prices increase (or reverse situations where all prices would decrease). Table 5 provides summary information on the price effects, showing the changes in the price level by country, and further broken down by domestic and foreign cars in each country. The price levels refer to weighted price indices, where the weights are the market shares before liberalization. Under non-cooperative pricing, liberalization would have the effect of raising the general car price level in most countries except in Germany, though the effects are very modest for most countries (third and sixth column of Table 5). The overall price increase (for all five countries) is between 0.3 and 0.6 percent. While the general price levels would not change much for the various countries, there are fairly substantial relative price changes within each country. This can especially be seen by breaking down the price changes by domestic and foreign cars, see the first and second, and fourth and fifth column of Table 5. In all countries the price level of domestic cars would drop while the price level of foreign cars would increase. We also broke down the price changes by market segment (not shown). While the price changes are somewhat stronger in the lower-end segments (subcompact and compact), there do not generally appear to be striking differences across market segments.

Now consider the price level changes under partially collusive pricing. Recall that we found that in most countries prices are set close to non-cooperative pricing, except in the 
U.K. where prices appear closer to fully collusive behavior. One can see that the changes in the price levels now show important differences between countries. Liberalization would raise the price level by between $4 \%$ and $15 \%$ in all countries except the U.K. In the U.K. the price level would drop by about $16-18 \%$. The intuition for these contrasting findings follows directly from the different pricing assumptions and the implied computed marginal costs and markups before liberalization. Under non-cooperative pricing, the systematic country-level international price differentials are largely driven by cost differences; markup differences only play a role for domestic versus foreign cars. Under partially collusive pricing, systematic country-level price differences are purely driven by markup differences instead of cost differences (by construction). It is therefore not surprising to see only modest countrylevel effects under non-cooperative pricing and strong country-level effects under partially collusive pricing.

Table 5. Percentage price changes after liberalization

(full national intrabrand competition before liberalization)

\begin{tabular}{|c|c|c|c|c|c|c|}
\hline & domestic & foreign & all & domestic & foreign & all \\
\hline & \multicolumn{6}{|c|}{ Non-cooperative pricing } \\
\hline & \multicolumn{3}{|c|}{ Max. markup differential $\tau=12 \%$} & \multicolumn{3}{|c|}{ Max. markup differential $\tau=0 \%$} \\
\hline Belgium & - & - & 1.4 & - & - & 5.0 \\
\hline France & -2.1 & 2.8 & 0.1 & -4.8 & 6.8 & 0.4 \\
\hline Germany & -0.7 & 1.5 & -0.2 & -2.4 & 2.6 & -1.2 \\
\hline Italy & -3.8 & 4.0 & 1.6 & -4.8 & 7.6 & 3.8 \\
\hline U.K. & -2.6 & 1.7 & 0.1 & -3.6 & 2.4 & 0.2 \\
\hline \multirow[t]{3}{*}{ All } & -1.9 & 2.4 & 0.3 & -3.3 & 4.4 & 0.6 \\
\hline & \multicolumn{6}{|c|}{ Partially collusive pricing $(\phi)$} \\
\hline & \multicolumn{3}{|c|}{ Max. markup differential $\tau=12 \%$} & \multicolumn{3}{|c|}{ Max. markup differential $\tau=0 \%$} \\
\hline Belgium & - & - & 13.1 & - & - & 14.6 \\
\hline France & 5.8 & 10.6 & 7.9 & 6.5 & 12.1 & 9.0 \\
\hline Germany & 4.7 & 2.5 & 4.2 & 5.3 & 1.8 & 4.5 \\
\hline Italy & 2.9 & 4.6 & 4.1 & 6.2 & 4.5 & 5.0 \\
\hline U.K. & -15.1 & -16.4 & -15.9 & -17.6 & -18.9 & -18.4 \\
\hline All & -0.2 & -0.8 & -0.2 & 0.1 & -1.5 & -0.3 \\
\hline
\end{tabular}

Note: Results are percentage changes of price indices. Price indices are weighted average price levels using the sales before liberalization as weights.

Now consider the effects from liberalization on consumer surplus, producer surplus and total welfare, as summarized in Table 6. Under non-cooperative pricing consumer surplus 
would drop by 244 million Euro or $4.2 \%$ in Belgium, and by 736 million Euro, or $3.5 \%$ in Italy (when $\tau=0 \%$, i.e. full elimination of discrimination). In all other countries consumer surplus would increase, but the effects are small (in the range of $0.5-1.8 \%$ ). This shows that, consistent with the previously discussed price indices, under non-cooperative pricing the overall effects on consumers are relatively modest, despite the substantial underlying changes in relative prices (in particular domestic versus foreign). Under partially collusive pricing the overall effects on consumers are considerably more important. Consumers from all countries except the U.K. would loose, e.g. by up to 1.8 billion Euro in France and Germany. U.K. consumers would gains substantially. As before, this follows from the fact that the large existing international price differentials between the U.K. and the rest of Europe are now entirely attributed to markup differences.

The effects from liberalization on producer surplus are similar whether one considers noncooperative or collusive pricing. If markup differentials would be reduced to a maximum of $12 \%$, then producer surplus would (slightly) increase, while if markup differentials would be fully eliminated, then producer surplus would (again slightly) decrease. Finally, the effects from liberalization on total welfare are modest under non-cooperative pricing (negligible increase or decrease), and quite large under partially collusive pricing (increase by 1.6-2.0 billion Euro).

This discussion shows the importance of knowing the causes behind the large price differentials in the European Union. If conduct is similar in all countries (non-cooperative), then liberalization may lead to substantial changes for individual car prices, as illustrated by the differences between domestic and foreign cars. But the overall effects on consumers in the various countries, on producers and total welfare would be modest. In contrast, when cross-country differences in conduct lie behind the systematic international price differentials, then the overall effects on consumers, producers and total welfare may be substantial. In light of the previous discussion that cost-differences are presumably less than implied by non-cooperative pricing so that conduct may differ at least partly across countries, one might conjecture that the actual effects from liberalization lie somewhere in between the two extremes. 
Table 6. Welfare changes after liberalization

(full national intrabrand competition before liberalization)

\begin{tabular}{ll|rr|rr|rr|rr}
\hline & & \multicolumn{3}{|c|}{ Non-cooperative pricing } & \multicolumn{3}{c|}{ Partially collusive pricing $(\phi)$} \\
\cline { 3 - 10 } & \multicolumn{2}{|c|}{$\tau=12 \%$} & \multicolumn{2}{c}{$\tau=0 \%$} & \multicolumn{2}{c}{$\tau=12 \%$} & \multicolumn{2}{c}{$\tau=0 \%$} \\
\hline \hline$\Delta C S$ & Belgium & -63 & $(-1.10)$ & -244 & $(-4.22)$ & -662 & $(-11.49)$ & -731 & $(-12.68)$ \\
& France & 76 & $(0.32)$ & 167 & $(0.69)$ & -1632 & $(-6.71)$ & -1820 & $(-7.48)$ \\
& Germany & 154 & $(0.34)$ & 806 & $(1.80)$ & -1801 & $(-4.01)$ & -1844 & $(-4.11)$ \\
& Italy & -315 & $(-1.47)$ & -736 & $(-3.45)$ & -509 & $(-2.38)$ & -595 & $(-2.78)$ \\
& U.K. & 101 & $(0.39)$ & 122 & $(0.47)$ & 6133 & $(23.46)$ & 7258 & $27.76)$ \\
& All & -47 & $(-0.04)$ & 117 & $(0.09)$ & 1530 & $(1.25)$ & 2270 & $(1.85)$ \\
\hline$\Delta P S$ & All & 84 & $(0.15)$ & -162 & $(-0.29)$ & 101 & $(0.16)$ & -238 & $(-0.38)$ \\
\hline$\Delta W$ & All & 38 & $(0.02)$ & -45 & $(-0.03)$ & 1631 & $(0.88)$ & 2030 & $(1.10)$
\end{tabular}

Note: Results are changes expressed in millions of Euro. Percentage changes are in parentheses.

\subsection{Limited national intrabrand competition before liberalization}

We now consider the situation in which the current system effectively limits national intrabrand competition before liberalization. In this case the impact of liberalization will be the combined effect of increasing both national and international intrabrand competition. Before looking at the effects on consumer surplus, producer surplus and total welfare (analogous to the previous section), we address a somewhat different question. We ask whether liberalization would raise or reduce the manufacturers' profits. An answer to this question can shed light on whether manufacturers would want to have adopt the vertical restraints even in the absence of efficiencies, such as public good aspects in providing retail services.

Section 3.2 analyzed manufacturers' pricing under limited national intrabrand competition. As mentioned, Rey and Stiglitz (1995) show that the double marginalization effect mitigates competition between manufacturers. This may increase the manufacturers' profits and work as a tacit collusion device, especially when competition is intense (e.g. when products are close substitutes). Vertical restraints that limit national intrabrand competition may therefore sometimes not require any efficiencies to be profitable, in contrast to the well-known case where the upstream manufacturer is a monopoly.

But Rey and Stiglitz' analysis only applies to a single market (or to multiple identical markets). With multiple markets and different local demand conditions, the restraints may also be adopted as a mechanism to limit intrabrand competition across markets in order to enforce price discrimination across these markets. In sum, the restraints may be prof- 
itable even absent efficiencies, for two potentially anti-competitive reasons: to limit national intrabrand competition (tacit collusion) and to limit international intrabrand competition (price discrimination). An empirical analysis on the profitability of these possible incentives is therefore necessary, and we take the following approach. Based on the observation that the existing system has been adopted as the result of a cooperative agreement between all car manufacturers in the industry (the block exemption), we compare the manufacturers' joint profits before and after removing reform. ${ }^{8}$

Table 7 shows the results. The first row shows the changes in profits when liberalization hypothetically only has the effect of creating full national intrabrand competition, and has no impact on the extent of international intrabrand competition. In this case, the only profit source from existing system is the tacit collusion device identified by Rey and Stiglitz (so $\tau$ is assumed sufficiently high, so that liberalization involves no binding markup constraints). The first row shows that liberalization would increase joint profits by between 2 and 3 billion Euro annually. More detailed calculations showed that liberalization would lower the manufacturers' profit margins. But this would be accompanied by a high increase in sales, so that the overall effect is an increased profit. This might lead one to conclude that the current system is not profitable absent efficiencies, so that efficiencies must be present. Yet in light of the above it is necessary to also look at the second and third rows, which account for the fact that the current system also has an impact on the extent of international intrabrand competition (as before, modelled by setting $\tau=12 \%$ or $\tau=0 \%$ ). The results show that in both cases the profits would still increase, under non-cooperative pricing even by more. Hence, it turns out that the current system is not profitable to the manufacturers on anticompetitive grounds, even if one accounts for both the tacit collusion and international price discrimination mechanisms. Hence, if one is to argue that the scenario of limited national intrabrand competition before liberalization is the valid one, one has to be consistent and accept that efficiencies must also be involved, since the firms would otherwise presumably not have cooperated to obtain the exemption in the first place.

\footnotetext{
${ }^{8}$ This approach would be more difficult to justify during the seventies, when firms formed bilateral agreements with their dealers. In this case, it would be more suitable to directly follow Rey and Stiglitz' noncooperative approach, and compute each individual manufacturer's change in profits when it would remove the restraints, given that all other manufacturers keep it.
} 
Table 7. Changes in manufacturers' profits from liberalization

\begin{tabular}{l|cc}
\hline \multicolumn{3}{c}{ (limited national intrabrand competition before liberalization) } \\
\hline & Non-cooperative pricing & Partially collusive pricing $(\phi)$ \\
\hline$\tau$ is high & 3032 & 2174 \\
$\tau=12 \%$ & 3309 & 1024 \\
$\tau=0 \%$ & 3125 & 1284
\end{tabular}

Note: Results are changes expressed in millions of Euro.

Having established that the scenario of limited national intrabrand competition before liberalization only applies if there are efficiencies, we now look at the various welfare effects from liberalizing the distribution system. The results have to be taken with great caution since they would need to be balanced against possibly large efficiency losses. The general price level in Europe would decrease by between $8-10 \%$ in most countries, especially in the U.K. under partially collusive pricing. (Results, the analogue of Table 5 , are not shown).

Table 8 shows the changes in consumer surplus, producer surplus and total welfare caused by liberalization. Notice first that producer surplus (the sum of both the manufacturers' and retailers' profits) drops substantially because of liberalization, whether price discrimination is eliminated partly $(\tau=12 \%)$ or completely $(\tau=0 \%)$. In contrast, consumer surplus would increase substantially, by about $10-13 \%$ at the European level (consistent with the percentage drops in the general price levels reported before). Only consumer in Belgium would be worse off, at least under partially collusive pricing. The overall effect on total welfare is a substantial increase, by between 6 and 8 billion Euro. At first sight, it appears that the conclusions obtained under the scenario of full national intrabrand competition before liberalization differ rather drastically. Recall, however, that we found that the currently considered scenario must involve fairly large efficiencies. Hence liberalizing the system if the current scenario applies, may involve the elimination of considerable efficiencies. If one would account for these, the total welfare effects may actually lie much closer to the ones obtained under the previous scenario. 
Table 8. Welfare changes after liberalization.

(limited national intrabrand competition before liberalization)

\begin{tabular}{ll|rr|rr|rr|rr}
\hline & & \multicolumn{3}{|c|}{ Non-cooperative pricing } & \multicolumn{3}{c|}{ Partially collusive pricing } \\
\cline { 3 - 10 } & \multicolumn{2}{|c|}{$\tau=12 \%$} & \multicolumn{2}{|c|}{$\tau=0 \%$} & \multicolumn{2}{c}{$\tau=12 \%$} & \multicolumn{2}{c}{$\tau=0 \%$} \\
\hline \hline$\Delta C S$ & Belgium & 303 & $(5.25)$ & 102 & $(1.78)$ & -162 & $(-2.82)$ & -205 & $(-3.55)$ \\
& France & 2508 & $(10.31)$ & 2603 & $(10.71)$ & 583 & $(2.40)$ & 415 & $(1.70)$ \\
& Germany & 5344 & $(11.92)$ & 6097 & $(13.60)$ & 2697 & $(6.02)$ & 2678 & $(5.97)$ \\
& Italy & 1379 & $(6.45)$ & 885 & $(4.14)$ & 2634 & $(12.33)$ & 2130 & $(9.97)$ \\
& U.K. & 2541 & $(9.72)$ & 2567 & $(9.82)$ & 9274 & $(35.46)$ & 10403 & $(39.78)$ \\
& All & 12074 & $(9.86)$ & 12254 & $(10.01)$ & 15027 & $(12.27)$ & 15419 & $(12.60)$ \\
\hline$\Delta P S$ & All & -5394 & $(-8.25)$ & -5686 & $(-8.70)$ & -7324 & $(-10.54)$ & -7026 & $(-10.12)$ \\
\hline$\Delta W$ & All & 6680 & $(3.56)$ & 6567 & $(3.50)$ & 7702 & $(4.01)$ & 8393 & $(4.37)$
\end{tabular}

Note: Results are changes expressed in millions of Euro. Percentage changes are in parentheses.

\section{Conclusions and extensions}

Our analysis has investigated how the liberalization of vertical restraints may affect consumer surplus, producer surplus and total welfare. Some of our main findings are as follows. If the existing system already entails sufficient national intrabrand competition, then liberalization mainly improves international intrabrand competition, and so leads to a reduction in international price discrimination. Total total welfare may increase by an amount between zero and 1.6-2 billion Euro per year. If the existing system effectively limits national intrabrand competition, then liberalization may lead to both reduced international price discrimination and to the elimination of tacit collusion. The computed welfare gains become much larger, yet one must now also account for potentially large efficiencies losses since the existing system would be hard to rationalize without efficiencies from the industry's point of view.

The analysis may be extended in several ways. First, one might account for the fact that industry restructuring may take place in response to liberalization. Assuming that firms incur fixed costs, they may no longer be able to recover those after liberalization. One might investigate what the effects would be when liberalization measures triggers mergers or other horizontal agreements. Second, it would be interesting to analyze the effects in high tax countries in more detail. We have focused here on the incentives for international price discrimination induced by the current system. Yet an issue that has received less attention is that the current system also provides incentives to individual countries to implement tax discrimination. While V.A.T. is now similar between countries, other taxes are far from being 
harmonized across Europe. Some countries apply registration and other taxes amounting to over $100 \%$ of the purchase price. These are countries that typically do not have much local production (e.g. Danmark, Greece). It is clear that the incentives for tax discrimination by governments may be seriously reduced when the distribution system is liberalized. Firms currently charge lower markups in the high tax countries to stimulate demand, but they would no longer be willing to do so in an integrated market as it would attract too many foreign consumers. Hence markups would increase in the high tax countries, which would lead to lower demand and tax revenues. This would in turn induce local governments to bring their taxes more in line with those of other European countries, possibly implying important additional welfare changes.

\section{References}

Armstrong, M. and J. Vickers, 2002, Competitive Price Discrimination, RAND Journal of Economics.

Berry, S., 1994, Estimating discrete-choice models of product differentiation, RAND Journal of Economics, 25, 242-262.

Berry, S., J. Levinsohn and A. Pakes, 1995, Automobile Prices in Market Equilibrium, Econometrica, 841-890.

Berry, S., and A. Pakes, 2001, Additional Information for: "Comment on "Alternative models of demand for automobiles" by Charlotte Wojcik", Economics Letters, 74, 43-51.

Berto Villas-Boas, S., 2002, Vertical Contracts between Manufacturers and Retailers: an Empirical Analysis, mimeo, University of California, Berkeley.

BEUC, 1992, Parallel Imports for Cars in the EC, BEUC/222/92, Brussels.

Bresnahan, T. F., S. Stern and M. Trajtenberg, 1997, Market Segmentation and the Sources of Rents from Innovation: Personal Computers in the Late 1980s, RAND Journal of Economics, 28, S17-44.

Competition Commission, 2000, New Cars: a Report on the Supply of New Motor Cars within the U.K.

Corts, K., 1998, Third-Degree Price Discrimination in Oligopoly: All-Out Competition and Strategic Commitment, RAND Journal of Economics, 29, 306323. 
Davidson, R., M. Dewatripont, V. Ginsburgh, and M. Labbé, 1989, On the Welfare Effects of Anti-Discrimination Regulations in the EC Car Market, International Journal of Industrial Organization, 7, 205-230.

European Commission, 2000, Report on the Evaluation of Regulation (EC) No 1475/95 on the application of Article 85(3) of the Treaty to Certain Categories of Motor Vehicle Distribution and Servicing Agreements.

Goldberg, P.K., 1995, Product Differentiation and Oligopoly in International Markets: The Case of the U.S. Automobile Industry, Econometrica, 63, 891951.

Goldberg, P.K. and F. Verboven, 2001, The Evolution of Price Dispersion in the European car market, Review of Economic Studies, 68, 811-848.

Hausman, J.A., G. Leonard and J.D. Zona, 1994, Competitive Analysis with Differentiated Products, Annales d'Economie et de Statistique, 34, 159-180.

Holmes, T.J., 1989, The Effects of Third-Degree Price Discrimination in Oligopoly, American Economic Review, 79, 244-250.

Ivaldi, M. and F. Verboven, 2001, Quantifying the Effects from Horizontal Mergers in European Competition Policy, C.E.P.R. Discussion Paper 2697.

Jayaratne, J. and C. Shapiro, 2000, Simulating Partial Asset Divestitures to 'Fix' Mergers, International Journal of the Economics of Business, 7, 179-200.

McFadden, D., 1978, Modeling the Choice of Residential Location, in: A. Karlqvist, L. Lundqvist, F. Snickars and J. Weibul, eds., Spatial Interaction Theory and Planning Models, New York: North-Holland.

Nevo, A., 2000, Mergers with Differentiated Products: the Case of the Readyto-Eat Cereal Industry, RAND Journal of Economics, 31, 395-421.

Nevo, A., 2001, Measuring Market Power in the Ready-to-Eat Cereal Industry, Econometrica, 69(2), 307-342.

Petrin, A., 2002, Quantifying the Benefits of New Products: the Case of the Minivan, Journal of Political Economy.

Pinkse, J. and M. Slade, 2001, Mergers, Brand Competition and the Price of a Pint, University of British Columbia Working Paper.

Rey, P. and J. Stiglitz, 1995, The role of Exclusive Territories in Producers' Competition, RAND Journal of Economics, 26, 3, 431-451. 
Small, K.A., 1987, A Discrete Choice Model for Ordered Alternatives, Econometrica, 55, 409-24.

Stole, L. A., 2001, Price Discrimination in Competitive Environments, mimeo, University of Chicago.

Sudhir, K., 2001, Structural Analysis of Manufacturer Pricing in the Presence of a Strategic Retailer, Marketing Science, 20(3), 244-264.

Thisse, J.F. and X. Vives, 1988, On the Strategic Choice of Spatial Price Policy, American Economic Review, 78, 122-137.

Verboven, F., 1996, International Price Discrimination in the European Car Market, RAND Journal of Economics, 27, 240-68.

Villas-Boas, J.M. and Y. Zao, 2002, The Ketchup Market Place: Retailer, Manufacturers and Individual Consumers, mimeo, University of California, Berkeley.

Werden, G. and L. Froeb, 1994, The Effects of Mergers in Differentiated Products Industries: Logit Demand and Merger Policy, 10, 407-426.

\section{Appendix.}

\subsection{The selective and exclusive distribution system}

This part of the appendix provides a detailed discussion on the essential features of selectivity and exclusivity, to demonstrate their impact on national and international intrabrand competition.

Until 1985 the relationships between the car manufacturers and their dealers were regulated through individual exemption decisions by the European Commission. In 1985, the Commission decided to adopt a block exemption regulation, Regulation 123/85, applicable to the whole industry. The block exemption allowed for two main restrictions in distribution: selectivity and territorial exclusivity. In addition, non-compete clauses (or "exclusive dealing" arrangements) and other restrictions were allowed. In 1995, the Commission adopted a new block exemption, Regulation 1475/95, expiring in September 2002. The basic principles remained unchanged, though some of the restrictions were relaxed to stimulate competition. We summarize the main properties of the distribution system as it exists since 1995. For further details, including a comparison between the 1985 and 1995 system, we refer to the European Commission (2000) and the U.K. Competition Commission (2000). 


\section{Selectivity and exclusivity}

Selective and exclusive distribution agreements have in common that they restrict the number of authorized distributors and the possibilities of resale. ${ }^{9}$ The difference lies in how these restrictions work, see Table 1 for a summary. Selectivity means that each manufacturer can set qualitative and quantitative criteria on its distributors. Qualitative criteria are, for example, minimum standards as regards training of staff, advertizing and storage, and most notably, the obligation to provide after-sales repair and maintenance services. Quantitative criteria allow the manufacturer to restrict the total number of dealers and to impose annual sales targets. To protect the selectivity of the distribution system, the manufacturer can prohibit its dealers to sell cars to independent resellers. Dealers may thus only sell to endconsumers, to intermediaries with a written authorization from consumers, or to other dealers within the manufacturer's network.

Territorial exclusivity refers to the manufacturers' right to appoint only one dealer in a geographically limited territory. The appointed dealers must not maintain branches outside their own contract territory, i.e. a "location clause" is permitted. Dealers have to concentrate their marketing efforts on their own territory and are restricted from an active sales policy in other territories. While they can advertize in media that cover a wider area than their own territory, personalized advertizing campaigns outside their territory are forbidden.

We focus on the two main potential anti-competitive effects from the selective and exclusive distribution system. Both effects concern a reduction of intrabrand competition, i.e. competition between dealers selling the same brand. First, the system may restrict international intrabrand competition, i.e. opportunities for cross-border trade, and thus lie at the basis of large international price differentials. Second, the system has the potential of reducing national intrabrand competition and thereby creating tacit collusion among the manufacturers.

Table 1. Selective versus exclusive distribution

\begin{tabular}{l|ll}
\hline Distribution & \multicolumn{3}{|c}{ Restriction } & \multicolumn{2}{|c}{ imposed on } \\
& \multicolumn{1}{|c}{ authorized distributors } & \multicolumn{1}{c}{ possibilities of resale } \\
\hline Selective & qualitative and quantitative criteria & no sales to independent reseller \\
Exclusive & geographic territory & no active selling in other territory
\end{tabular}

\section{Effects on international intrabrand competition and price discrimination}

\footnotetext{
${ }^{9}$ See the Commission Notice in O.J. 2000/C 291/01 of 13.10.2000 on Guidelines on Vertical Restraints, paragraph (184).
} 
When selectivity and territorial exclusivity are not combined, the opportunities for international intrabrand competition, or cross-border trade, are not seriously affected. Suppose there is selectivity without exclusivity. While the selected dealers are then restricted from selling to independent resellers, they can set up their own branches abroad to take advantage of existing price differentials. Furthermore, the dealers can engage in active cross-border sales policies such as personalized advertizing. Conversely, suppose there is exclusivity without selectivity. Although the exclusive dealers cannot set up their own branches abroad, they can sell to independent resellers who may exploit the price differentials. Hence when selectivity and exclusivity are not combined, international price differentials are constrained by the arbitrage activities of either the foreign branches of the selected dealers or the independent resellers.

In contrast, when selectivity and exclusivity are both adopted together, the possibilities for cross-border trade become limited. It can then only take place directly by end-consumers, by intermediaries with a written authorization from consumers, or by dealers within the manufacturer's network. An "availability clause" aims to guarantee the cross-border supply. It states that dealers should be able to obtain cars with foreign specifications from their manufacturers (e.g. right-hand drive cars for the U.K. market). In practice, however, the system of quantitative sales targets (including the associated bonus schemes) severely limits the cross-border supply and thus the possibilities for arbitrage. Most manufacturers link the allocation of new cars to their dealers to the agreed sales targets. As a result, the dealers cannot supply any amount they want; they are constrained by the sales targets. They are thus inclined to first serve their local customers to whom they can also offer after-sales services. Supply is further limited because the dealers must sell the whole model range. This means that dealers can in practice only get sufficient numbers of an attractive model if they also take a number of less attractive models. The conclusion is that the system does not hamper the availability of cars to customers within the dealers' territory, but may lead to long delivery lags (or excessive surcharges) for other customers.

To which extent do end-consumers, intermediaries and other dealers face other restrictions, in addition to the limited cross-border supply?

(i) The rights of end-consumers to purchase a car abroad are in principle best protected. A 1985 Commission Notice formally states that consumers who purchase their car abroad must not face excessive delivery lags or refusals to carry out warranty works. ${ }^{10}$ The benefits from the distribution system may be withdrawn

\footnotetext{
${ }^{10}$ See the Commission Notice in O.J. 1985/C17/03 of 18.1.1985 on the rights of consumers and the tolerance levels for price differentials.
} 
if international price differentials exceed $12 \%$ for more than a year, or exceed $18 \%$ for a shorter period. In practice, foreign consumers have in fact often faced long delivery lags or have had to pay higher prices than domestic consumers, see BEUC (1992) and its previous studies for anecdotal evidence. Furthermore, international price differentials have regularly exceeded the thresholds without initiating a formal investigation by the Commission.

(ii) The rights of intermediaries with a written authorization from end-consumers are formally restricted by a 1991 Notice. ${ }^{11}$ To ensure that they do not act like independent resellers, they must avoid carrying a common name; they must not use supermarkets as outlets; and they must quote their prices only as "best estimates". Furthermore, intermediaries and dealers may not establish privileged relationships with each other, in the form of favorable conditions or sales amounts exceeding $10 \%$ of the dealers sales.

(iii) The dealers who want to purchase from other dealers of their network also face additional restrictions. The sales targets are not only responsible for the limited cross-border supply as discussed above. The U.K. Competition Commission (2000) reports an interesting additional effect. Many manufacturers seem to determine whether the sales targets are met by counting only the cars that the dealers obtain directly from the manufacturers, and not the cars they obtain from foreign dealers. Dealers will therefore have a great difficulty in meeting their sales target if most of their sales to local customers are sourced from foreign dealers rather than from the manufacturer. Note that a similar effect would arise if the manufacturer would exclude the sales sourced from foreign dealers when determining the bonus payments, but this is a black practice according to the regulation.

In summary, this discussion makes clear the selective and exclusive distribution system contains several restrictions that limits international intrabrand competition, or cross-border trade. Further support for this conclusion comes from the large international price differentials together with the low extent of parallel imports (in the range of $0-2 \%$ of total sales), as previously documented by e.g. BEUC (1992) and Goldberg and Verboven (2001).

\section{Effects on national intrabrand competition and tacit collusion}

Selectivity and exclusivity may have an additional anti-competitive effect, relating to intrabrand competition within a country. As analyzed by Rey and Stiglitz (1995), a lim-

\footnotetext{
${ }^{11}$ See the Commission Notice in O.J. 1991/C 329 of 18.12.1991 on the obligations of intermediaries.
} 
ited degree of national intrabrand competition creates a double marginalization effect, which serves to reduce the degree of competition between the manufacturers (interbrand competition). As a result, both the dealers' retail prices and the manufacturers' wholesale prices may be higher than the noncooperative Bertrand prices, and manufacturers may succeed in obtaining larger profits, a form of tacit collusion between the manufacturers.

Does the current system effectively reduce the extent of intrabrand competition within a country, and thus potentially create tacit collusion? It is not obvious that this is the case. As discussed above, dealers can engage in non-personalized advertizing campaigns outside the territory. The U.K. Competition Commission (2000) quotes the number of $39 \%$ as the proportion of out-of-territory sales. Based on the fact that most of the population lives in urban areas and commutes to different areas, the Competition Commission interprets this to be a small proportion, and concludes that intrabrand competition is relatively weak; see 2.117 and 2.322 in Competition Commission (2000). Nevertheless, the proportion suggests that consumers do purchase in other territories, so that intrabrand competition is potentially present to at least some extent.

\section{Other features of the distribution system}

The manufacturers can also place additional restrictions to their dealers, apart from selectivity and territorial exclusivity. In particular, they are allowed to adopt non-compete clauses, or "exclusive dealing" arrangements. This limits the dealers' possibilities to sell cars from different manufacturers. Multiple brands can only be sold if this is done under separate management, in the form of a distinct legal entity and in separate showrooms to avoid confusion between brands. In practice, most dealers sell only one brand; exceptions occur in the rural areas of the Nordic countries.

The manufacturers should allow access to their dealer network by independent spare part producers. The dealers thus have the right to use spare parts from these suppliers, provided that they are of "matching quality".

Although the selectivity imposes dealers to provide after sales services, independent repairers may also be active. They should have access to the necessary technical information so as to provide maintenance and repair services. Repairs that fall under the warranty are to be carried out by the authorized dealers.

\section{The 2002 proposals for liberalization}

In light of the expiration of the current distribution system in September 2002, the Commission has proposed a revised system. On the one hand, the new system is potentially more liberal than the current system; on the other hand, it gives the manufacturers more choice. The main proposal is to allow the manufacturers to impose either selectivity or exclusivity on 
their dealers, but no longer a combination of both. Note that this is effectively a stricter than the general exemption granted to vertical restraints. This is because of the Commission's fear of cumulative effects, i.e. the competitive effects when a large group of firms adopts the vertical restraints simultaneously. More specifically, if manufacturers adopt a selective agreement, their dealers can open foreign outlets, since they are no longer subject to a location clause. ${ }^{12}$ If manufacturers adopt an exclusive agreement, dealers have the right to sell to independent resellers, who do not need a written authorization from consumers. ${ }^{13}$ Furthermore, some of the conditions of selectivity and exclusivity are weakened. For example, the intermediaries who can trade under selectivity provided they have a written consumer authorization, are no longer restricted to purchase at most $10 \%$ of a dealer's total sales. Similarly, manufacturers can no longer impose sales targets (and bonus schemes) based on a territory that is smaller than the E.U. This should prevent the risk of a limited supply to dealers selling intensively abroad.

Other proposals are to facilitate the dealers' possibilities to sell cars from different manufacturers, and to reduce the link between new car sales and after-sales services. Although all of these proposals may affect the nature of competition in the market, we choose to focus on the main proposal, relating to selectivity and territorial exclusivity. Our focus also reflects the Commission's own interests. Before publishing its reform proposals, the Commission had requested a comparative study (carried out by Andersen) to evaluate the effects from five alternative distribution systems, each being a different combination of selectivity and exclusivity.

\subsection{Constrained Nash equilibrium}

This part of the appendix illustrates the computation of a constrained candidate Nash equilibrium. Suppose all constraints are nonbinding, except product $j$ 's constraint for country pair $(1,2)$, for which:

$$
(1+\tau)\left(p_{j 2}-\widehat{m c}_{j 2}\right)-\left(p_{j 1}-\widehat{m c}_{j 1}\right)=0 .
$$

In this case, the only nonzero Lagrange multiplier is $\lambda_{j 12}$. Hence the first-order conditions with respect to price reduce to the standard unconstrained first-order conditions:

\footnotetext{
${ }^{12}$ The abolishment of the location clause is subject to a transition period until 1 October 2005. Furthermore, it only applies to passenger cars, and not to trucks, buses and coaches.

${ }^{13}$ One might argue that the possibility to sell to independent resellers undermines the principle of territorial exclusivity. However, the independent resellers retain a substantial competitive disadvantage against the authorized exclusive dealers, who have faster access to supply, etc ...
} 


$$
s_{j^{\prime} m^{\prime}}\left(p_{m^{\prime}}\right)+\sum_{k \in F_{f m^{\prime}}}\left(p_{k m^{\prime}}-\widehat{m c}_{k m^{\prime}}\right) \frac{\partial s_{k m^{\prime}}\left(p_{m^{\prime}}\right)}{\partial p_{j^{\prime} m^{\prime}}}=0,
$$

for all $j^{\prime} \neq j$, or for $j^{\prime}=j$ and $m^{\prime} \neq 1,2$, while they reduce to:

$$
\begin{aligned}
& \left(s_{j 1}\left(p_{1}\right)+\sum_{k \in F_{f 1}}\left(p_{k 1}-\widehat{m c}_{k 1}\right) \frac{\partial s_{k 1}\left(p_{1}\right)}{\partial p_{j 1}}\right) L_{1}=\lambda_{j 12}, \\
& \left(s_{j 2}\left(p_{2}\right)+\sum_{k \in F_{f 2}}\left(p_{k 2}-\widehat{m c}_{k 2}\right) \frac{\partial s_{k 2}\left(p_{2}\right)}{\partial p_{j 2}}\right) L_{2}=-(1+\tau) \lambda_{j 12},
\end{aligned}
$$

for product $j$ in markets 1 and 2. This can be interpreted as follows. Since $\lambda_{j 12} \geq 0$ (and assuming a concave profit function), the first equality implies that product $j$ 's price in market 1 is below its unconstrained optimum; the second equality implies that product $j$ 's price in market 2 is above its unconstrained optimum. Notice the importance of the market sizes $L_{1}$ and $L_{2}$. When $L_{1}$ is large relative to $L_{2}$, the price in market 1 will be close to (but still below) the unconstrained optimum in market 1 , whereas the price in market 2 will be far from (and above) the unconstrained optimum in market 2. The reverse conclusion holds when $L_{1}$ is small relative to $L_{2}$.

To compute the candidate Nash equilibrium, substitute $\lambda_{j 12}$ out of (18) to obtain:

$$
\begin{aligned}
& \left(s_{j 1}\left(p_{1}\right)+\sum_{k \in F_{f 1}}\left(p_{k 1}-\widehat{m c}_{k 1}\right) \frac{\partial s_{k 1}\left(p_{1}\right)}{\partial p_{j 1}}\right) L_{1}+ \\
& \left(s_{j 2}\left(p_{2}\right)+\sum_{k \in F_{f 2}}\left(p_{k 2}-\widehat{m c}_{k 2}\right) \frac{\partial s_{k 2}\left(p_{2}\right)}{\partial p_{j 2}}\right) \frac{1}{1+\tau} L_{2}=0
\end{aligned}
$$

The candidate Nash equilibrium is given by the solution $p^{*}$ to the system of equations given by (??)-(17)-(19). It remains to verify whether at the solution to this system (i) no active constraint is unjustified, i.e.:

$$
\lambda_{j 12}=\left(s_{j 1}\left(p_{1}^{*}\right)+\sum_{k \in F_{f 1}}\left(p_{k 1}^{*}-\widehat{m c}_{k 1}\right) \frac{\partial s_{k 1}\left(p_{1}^{*}\right)}{\partial p_{j 1}^{*}}\right) L_{1} \geq 0,
$$

and whether (ii) no inactive constraint is violated, i.e. $(1+\tau)\left(p_{j^{\prime} n}^{*}-\widehat{m c}_{j^{\prime} n}\right)-\left(p_{j^{\prime} m^{\prime}}^{*}-\widehat{m c}_{j^{\prime} n^{\prime}}\right)>$ 0 for all $j^{\prime} \neq j$, or for $j^{\prime}=j$ and $m^{\prime} \neq 1,2$. 
This example immediately generalizes to cases in which at most one constraint is binding for several products. When two or more constraints per product are binding, there are two or more nonzero Lagrange multipliers per product. These multipliers may be substituted out in an analogous way as in the above example. 